\title{
Glycerol/Glucose Co-Fermentation: One More Proficient Process to Produce Propionic Acid by Propionibacterium acidipropionici
}

\author{
Yin Liu $\cdot$ Yong-Guang Zhang $\cdot$ Ru-Bing Zhang $\cdot$ \\ Fan Zhang $\cdot$ Jianhang Zhu
}

Received: 21 January 2010/ Accepted: 18 May 2010/Published online: 11 June 2010

(C) The Author(s) 2010. This article is published with open access at Springerlink.com

\begin{abstract}
Cosubstrates fermentation is such an effective strategy for increasing subject metabolic products that it could be available and studied in propionic acid production, using glycerol and glucose as carbon resources. The effects of glycerol, glucose, and their mixtures on the propionic acid production by Propionibacterium acidipropionici CGMCC1.2225 (ATCC4965) were studied, with the aim of improving the efficiency of propionic acid production. The propionic acid yield from substrate was improved from 0.475 and $0.303 \mathrm{~g} \mathrm{~g}^{-1}$ with glycerol and glucose alone, respectively, to $0.572 \mathrm{~g} \mathrm{~g}^{-1}$ with co-fermentation of a glycerol/glucose mixture of $4 / 1(\mathrm{~mol} / \mathrm{mol})$. The maximal propionic acid and substrate conversion rate were $21.9 \mathrm{~g}^{-1}$ and $57.2 \%(\mathrm{w} / \mathrm{w})$, respectively, both significantly higher than for a sole carbon source. Under optimized conditions of fed-batch fermentation, the maximal propionic acid yield and substrate conversion efficiency were $29.2 \mathrm{~g} \mathrm{l}^{-1}$ and $54.4 \%(\mathrm{w} / \mathrm{w})$, respectively. These results showed that glycerol/glucose co-fermentation could serve as an excellent alternative to conventional propionic acid fermentation.
\end{abstract}

Y. Liu · Y.-G. Zhang · R.-B. Zhang · F. Zhang · J. Zhu ( $\bowtie)$ Key Laboratory of Biofuel, Qingdao Institute of Bioenergy and Bioprocess Technology, Chinese Academy of Sciences, 189 Songling Road, Qingdao 266101, Shangdong, China e-mail: zhujh@qibebt.ac.cn

Y. Liu

Graduate University of the Chinese Academy of Sciences, Beijing 100049, China

\section{Introduction}

Propionic acid, an important mold inhibitor and chemical intermediate, is widely used in industry and, in particular, in the food industry [19]. The global capacity for propionic acid was 349,000 tons per year in 2006 with a demand growth forecast at $2.5 \%$ per year to 2010 [19]. Currently, almost all propionic acid is produced by petrochemical processes, but propionic acid biosynthesis is expected to be a promising option due to its renewable raw sources and the overall increasing consumer demand for biological products. Although there has been great interest in producing propionic acid from biomass via fermentation by propionibacteria, the relatively low propionic acid concentration, yield, and production rate of this approach have presented major barriers for economical applications [14].

The carbon source is one of the most important nutritional factors in propionic acid production [4]. For growth and organic acid formation, the Propionibacterium strains are rather omnivorous with respect to carbon sources [8], but the particular carbon source has great influence on cell growth, substrate consumption, and byproduct formation [4]. Carbon sources affect the kinetics of propionic acid fermentation of $P$. acidipropionici through a cellular response that redistributes the composition of the fermentation end-products to achieve an oxidation-reduction (redox) balance [15]. The metabolic patterns resulting from different carbon sources during propionic acid fermentation have been elucidated using metabolic stoichiometric analysis and have demonstrated the existence of different control mechanisms [15]. To achieve maximal propionic acid production with efficient substrate conversion and decreased byproduct formation, carbon source optimization for propionic acid production should be explored further. 
Conventional propionic acid fermentation usually employs a single carbon source, and mixed carbon sources have been proposed as useful alternative. Commonly, a sole carbon source could not meet the requirements for propionibacteria growth and propionic acid production. Mixed carbon sources could enhance propionic acid production through changes in the kinetics of propionic acid fermentation and end-product compositions. In spite of the great variety of carbon sources that have been studied for propionic acid production, mixed carbon sources have rarely been considered [12].

The present study aimed to put forward a theory for glycerol/glucose cofermentation, as well as to develop a novel process for propionic acid production. The main objective of the investigation was to evaluate the advantages of using glycerol/glucose mixtures by $P$. acidipropionici in batch and fed-batch fermentations. As a result, glycerol/glucose mixtures were proposed to enhance propionic acid production and attain a more efficient production process.

\section{Materials and Methods}

\section{Bacterium and Medium}

Propionibacterium acidipropionici CGMCC1.2225 (ATCC4965), from the CGMCC collection (Beijing, China), was grown in a basic medium containing glucose, glycerol, or mixed substrates. The seed medium was TY medium ( $\mathrm{pH} 7.0$ ) [7] including $0.5 \%$ tryptic soy broth, $1 \%$ yeast extract, $0.25 \% \mathrm{~K}_{2} \mathrm{HPO}_{4}$, and $0.15 \% \mathrm{KH}_{2} \mathrm{PO}_{4}$. The medium for propionic acid production was TY medium supplemented with $4 \%$ glycerol (TYG medium), glucose (TYD medium), or glycerol/glucose mixtures (TYM medium).

\section{Culture}

Propionibacterium acidipropionici was precultured in $250 \mathrm{ml}$ penicillin flasks containing $100 \mathrm{ml}$ nitrogen-gassed and sterile TY medium, sealed with butyl rubber caps, and incubated on a reciprocal shaker $(150$ strokes $/ \mathrm{min})$ at $30^{\circ} \mathrm{C}$ for $48 \mathrm{~h}$. Unless otherwise noted, the fermentation was carried out in a 5-1 glass bioreactor (Biostat B plus, B. Braun, Germany) containing 21 of the production medium with anaerobic conditions created by initially sparging the medium with nitrogen. An inoculum of 5\% $(\mathrm{v} / \mathrm{v})$ was used. Temperature, $\mathrm{pH}$, and agitation speed were maintained at $30^{\circ} \mathrm{C}, 6.5$, and $150 \mathrm{rpm}$, respectively. All fermentations were performed in duplicate.
Assays

Dry cell weight $(\mathrm{DCW})$ was calculated from the $\mathrm{OD}_{600}$ value. One unit of $\mathrm{OD}_{600}$ was equivalent to $0.325 \mathrm{~g} \mathrm{l}^{-1}$ DCW. Glucose was determined using SBA-40 C immobilized enzyme biosensor (Institute of Biology, Shandong Academy of Sciences, China), and glycerol was determined using a colorimetric method [3]. Propanol, acetic acid, and propionic acid were quantitated by gas chromatograph (Varian 450-GC, USA), using a capillary column (FFAP; $25 \mathrm{~m} \times 0.25 \mathrm{~mm} \times 0.20 \mu \mathrm{m}$; USA), a flame ionization detector (FID), and the injection and detection ports set at $240^{\circ} \mathrm{C}$. The column oven temperature was initially at $80^{\circ} \mathrm{C}$ for $1.0 \mathrm{~min}$, increased at $25^{\circ} \mathrm{C} / \mathrm{min}$ for $1.6 \mathrm{~min}, 30^{\circ} \mathrm{C} / \mathrm{min}$ for $0.5 \mathrm{~min}, 15^{\circ} \mathrm{C} / \mathrm{min}$ for $3 \mathrm{~min}$, and held at $180^{\circ} \mathrm{C}$ for $1.0 \mathrm{~min}$. Determination of succinic acid was performed as described previously [17].

\section{Results and Discussion}

\section{Comparison of Glycerol and Glucose Fermentations}

The use of carbon sources with different oxidation states influences the kinetics of propionic acid fermentation [15]. Comparison of glycerol and glucose fermentations could provide better understanding of how cells respond to these substrates and distribute carbon flux. Batch cultures performed with $P$. acidipropionici on $40 \mathrm{~g}^{-1}$ glycerol or glucose were carried out, and selected parameters were shown in Table 1. The maximal concentration of propionic acid in the fermentation broth was $18.1 \mathrm{~g} \mathrm{l}^{-1}$ using glycerol as the sole carbon source, while only $11.5 \mathrm{~g} \mathrm{l}^{-1}$ was attained with glucose alone (Fig. 1). The production rate and propionic acid yield were $0.068 \mathrm{~g} \mathrm{l}^{-1} \mathrm{~h}^{-1}$ and $0.303 \mathrm{~g} \mathrm{~g}^{-1}$ of glucose, respectively, while using glycerol, both values were higher $\left(0.108 \mathrm{~g}^{-1} \mathrm{~h}^{-1}\right.$ and $0.475 \mathrm{~g} \mathrm{~g}^{-1}$, respectively). It appeared that glycerol was superior to glucose for propionic acid fermentation, but, when considering DCW, glucose was the preferred carbon source, $6.8 \mathrm{~g}^{-1}$ of DCW could be obtained, which was higher than that the $3.3 \mathrm{~g}^{-1}$ obtained with glycerol (Table 1; Fig. 1). Thus, it was logical to investigate the effects of glycerol/glucose mixtures on cell growth and propionic acid production by this bacterium.

According to previous studies $[5,9,11,12,18]$ and the Eqs. $1 \mathrm{a}$ and $1 \mathrm{~b}$ describing the single metabolism of glucose or glycerol to propionic acid, we concluded Fig. 2 to describe the co-metabolism process qualitatively, in which the values of the coefficients $\alpha$ and $\beta$ are variable to keep redox balance. 
Table 1 The analysis of parameters at different culture conditions

\begin{tabular}{lllll}
\hline Parameters & Glycerol & Glucose & $\begin{array}{l}\text { Glycerol/glucose co-fermentation } \\
\text { (the molar ratio of glycerol } \\
\text { to glucose was 4:1) }\end{array}$ & $\begin{array}{l}\text { Fed-batch fermentation } \\
\text { with glycerol/glucose } \\
\text { co-fermentation }\end{array}$ \\
\hline $\mathrm{DCW}\left(\mathrm{g} \mathrm{l}^{-1}\right)$ & & & $4.9 \pm 0.13$ & $5.2 \pm 0.11$ \\
Propionic acid $\left(\mathrm{g} \mathrm{l}^{-1}\right)$ & $3.3 \pm 0.12$ & $6.8 \pm 0.19$ & $21.9 \pm 0.72$ & $29.2 \pm 0.70$ \\
Acetic acid $\left(\mathrm{g} \mathrm{l}^{-1}\right)$ & $18.1 \pm 0.65$ & $11.5 \pm 0.45$ & $1.1 \pm 0.15$ \\
Succinic acid $\left(\mathrm{g} \mathrm{l}^{-1}\right)$ & $0.54 \pm 0.09$ & $2.57 \pm 0.12$ & $0.87 \pm 0.08$ & $1.57 \pm 0.05$ \\
Propanol $\left(\mathrm{g} \mathrm{l}^{-1}\right)$ & $1.10 \pm 0.05$ & $0.55 \pm 0.03$ & $1.19 \pm 0.04$ & $\mathrm{ND}$ \\
Propionic acid/acetic acid $\left(\mathrm{mol} \mathrm{mol}^{-1}\right)$ & 27.1 & $\mathrm{ND}$ & $\mathrm{ND}$ & 22.9 \\
Propionic acid yield $\left(\mathrm{g} \mathrm{g}^{-1}\right)$ & $0.475 \pm 0.017$ & $0.303 \pm 0.012$ & $0.572 \pm 0.018$ & $0.544 \pm 0.012$ \\
Propionic acid productivity $\left(\mathrm{g} \mathrm{l}^{-1} \mathrm{~h}^{-1}\right)$ & 0.108 & 0.068 & 0.152 & 0.152 \\
$\lambda$ (lag time, $\mathrm{h}$ ) & 4 & 6 & 2 & 2 \\
Substrate exhausted time $(\mathrm{h})$ & 168 & 168 & 144 & 2 \\
\hline
\end{tabular}

The average data of three independent experiments

$N D$ None detected

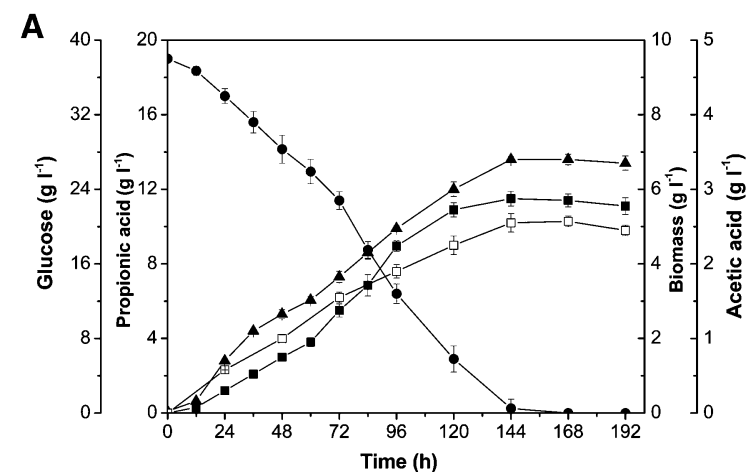

Fig. 1 Comparison of growth, substrate utilization, and product formation between glucose (a) and glycerol (b) batch fermentations. Biomass (closed triangle), glucose or glycerol (closed circle),

$$
\begin{gathered}
1.5 \mathrm{C}_{6} \mathrm{H}_{12} \mathrm{O}_{6} \rightarrow 2 \mathrm{C}_{3} \mathrm{H}_{6} \mathrm{O}_{2}+\mathrm{C}_{2} \mathrm{H}_{4} \mathrm{O}_{2}+1 \mathrm{CO}_{2} \\
+1 \mathrm{H}_{2} \mathrm{O}+6 \text { ATP } \\
1 \mathrm{C}_{3} \mathrm{H}_{8} \mathrm{O}_{3} \rightarrow \mathrm{C}_{3} \mathrm{H}_{6} \mathrm{O}_{2}+1 \mathrm{H}_{2} \mathrm{O}+2 \text { ATP }
\end{gathered}
$$

Biomass formation is accompanied by the production or consumption of NADH to maintain the hydrogen and redox balances. As shown in Table 2, glycerol is more reduced than glucose and biomass, and thus biomass formation from glycerol leads to net NADH production, while glucose leads to net NADH consumption (Fig. 2). In bacterial catabolism, regeneration of $\mathrm{NAD}^{+}$by reduction is required as carbon source oxidization occurs [2, 13]. As this Propionibacterium is an anaerobe, $\mathrm{NAD}^{+}$regeneration is achieved via the formation of reduced end-products, such as succinate and propanol (reductance degree: 6.0 ) and, as a result, NADH availability in the metabolic network could impact product formation.

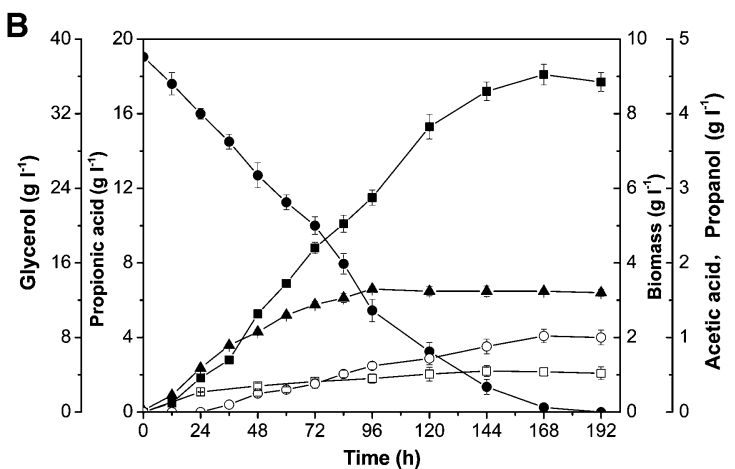

propionic acid (closed square), acetic acid (open square), and propanol (open circle); pH 6.5 controlled by $\mathrm{NaOH}$ addition; error bars data range about mean $(n \geq 2)$

\section{Batch Fermentation using Glycerol/Glucose Mixtures}

A set of batch cultivations with initial molar ratio of glycerol/glucose at $4 / 1,2 / 1$, and $1 / 1(\mathrm{~mol} / \mathrm{mol})$ were conducted in $250 \mathrm{ml}$ penicillin flasks under anaerobic conditions. The results indicated that the initial glycerol/glucose molar ratio played an important role in co-fermentation (Fig. 3) and that the optimal molar ratio was $4 / 1$.

Specific cell growth rate $\left(\mu_{x}\right)$ and specific propionic acid formation rate $\left(\mu_{\mathrm{p}}\right)$ were used to describe the propionic acid fermentation process. The profiles of $\mu_{x}$ and $\mu_{\mathrm{p}}$ had similar tendencies, with maximum values appearing at about $12 \mathrm{~h}$ (Fig. 4). Compared with glycerol or glucose fermentation, $\mu_{x}$ and $\mu_{\mathrm{p}}$ were higher in glycerol/glucose co-fermentation; these results suggested that mixed carbon sources were superior for promoting cell growth and propionic acid production (Fig. 4a). 
Fig. 2 Pathways of glycerol and glucose co-metabolism in Propionibacterium under anaerobic conditions (based on previous studies $[5,9,11,12$, 18])

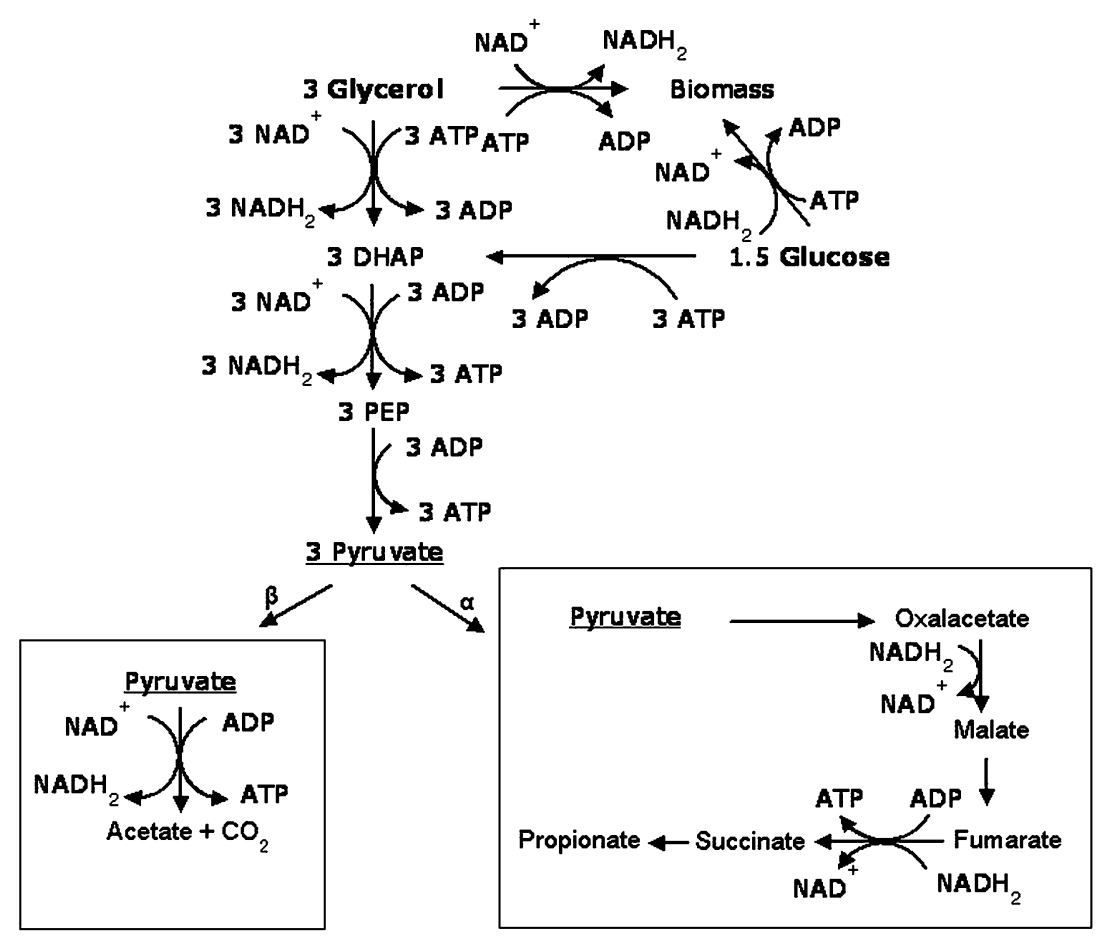

Table 2 The reductance degree of substrates or products

\begin{tabular}{lll}
\hline & $\begin{array}{l}\text { Degree of } \\
\text { reductance }\left(\gamma_{\mathrm{D}}\right)\end{array}$ & Reference \\
\hline Pyruvate & 3.33 & {$[16]$} \\
Succinate & 3.5 & {$[16]$} \\
Glucose & 4 & {$[16]$} \\
Acetate & 4 & {$[16]$} \\
Biomass & 4.29 & {$[10,11]$} \\
Glycerol & 4.67 & {$[16]$} \\
Propionate & 4.67 & {$[16]$} \\
Propanol & 6 & {$[16]$} \\
\hline
\end{tabular}

Glycerol/Glucose Co-Fermentation Strategy

for Propionic Acid Production

In order to evaluate propionic acid fermentation by yield and productivity parameters, the experiments were carried out with glycerol/glucose mixtures $(4 / 1, \mathrm{~mol} / \mathrm{mol})$ by using a fermentative batch model. Glycerol and glucose were found to be consumed almost simultaneously (Fig. 5). The propionic acid yield and maximum DCW obtained with glycerol fermentation were only 18.1 and $3.3 \mathrm{~g} \mathrm{l}^{-1}$, respectively, while a low propionic acid yield $\left(11.5 \mathrm{~g} \mathrm{l}^{-1}\right)$ and the maximum DCW $\left(6.8 \mathrm{~g} \mathrm{l}^{-1}\right)$ were observed with glucose fermentation (Table 1). Neither glycerol nor glucose was the optimal carbon source in terms of propionic acid production and cell growth. Thus, co-fermentation appeared to be an effective means of improving the propionic acid yield. Compared to single substrate fermentation, glycerol/glucose $(4 / 1, \mathrm{~mol} / \mathrm{mol})$ co-fermentation not only produced higher propionic acid $\left(21.9 \mathrm{~g} \mathrm{l}^{-1}\right)$, but also gave higher propionic acid yield from substrate. Glycerol/ glucose co-fermentation produced $20 \%$ more propionic acid than glycerol alone ( 0.572 vs. $\left.0.475 \mathrm{~g} \mathrm{~g}^{-1}\right)$ and $89 \%$ more propionic acid than glucose (0.572 vs. $\left.0.303 \mathrm{~g} \mathrm{~g}^{-1}\right)$ under the optimal conditions $(4 / 1, \mathrm{~mol} / \mathrm{mol})$ (Table 1$)$. The increased propionic acid production during co-fermentation could be attributed to decreased byproduct production as well as the high fraction of carbon recovered as propionic acid.

Himmi et al. (2000) [7] reported that propanol production by $P$. acidipropionici was higher from glycerol than glucose, but the present results demonstrated that $P$. acidipropionici CGMCC1.2225 could form propanol $\left(1.02 \mathrm{~g} \mathrm{l}^{-1}\right)$ from glycerol but not from glucose (Table 1). In addition, propanol has never been detected during glycerol/glucose co-fermentation, such that co-metabolism of both substrates appears to avoid propanol formation; the toxicity of propanol is thus avoided.

Acetic acid formation by $P$. acidipropionici was about $80 \%$ lower with glycerol as a substrate than glucose (Fig. 1). It is well known that glycerol and propionic acid have essentially the same redox state (reductance degree, 4.67), and thus can maintain a redox balance without production of another compensating metabolite [6]. In contrast, propionic acid production from glucose necessarily leads to 

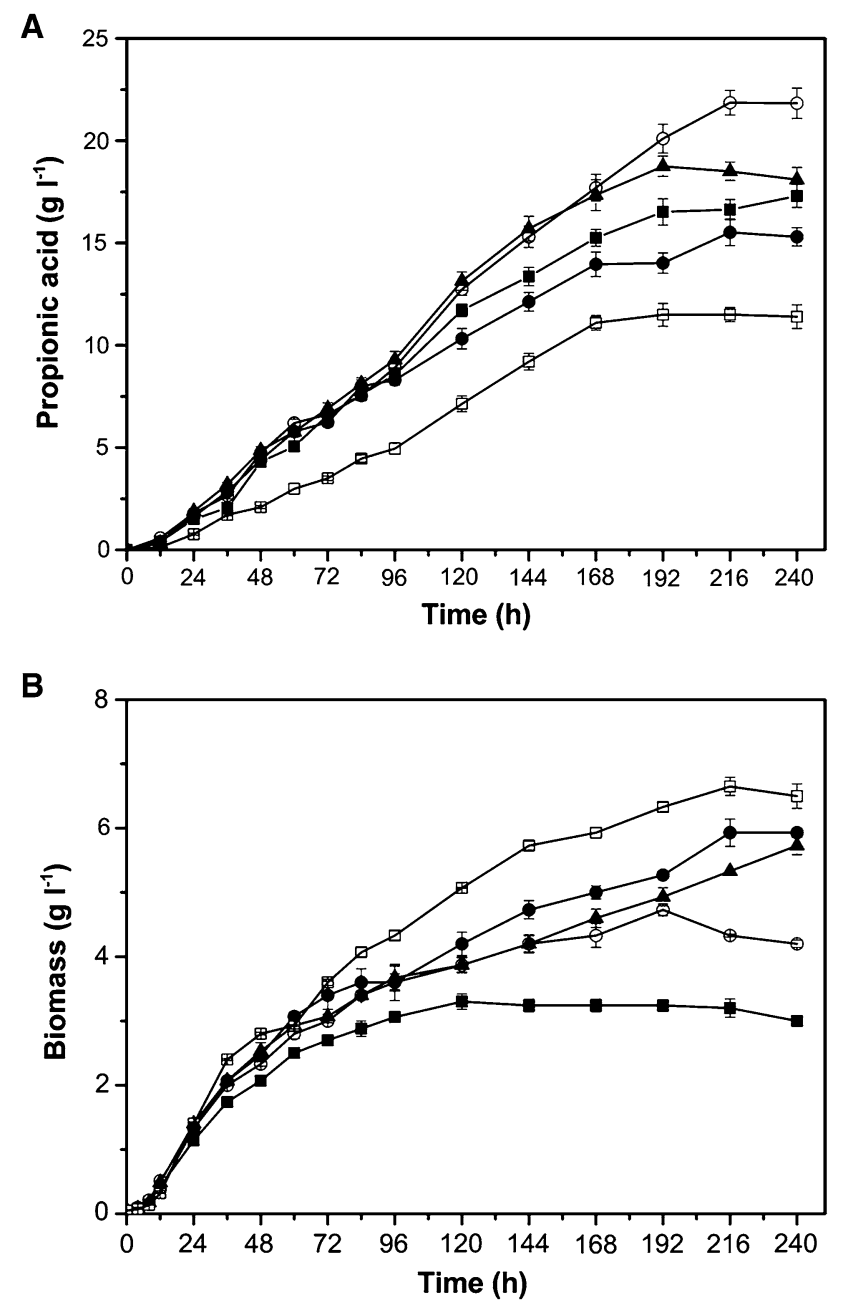

Fig. 3 Time course of propionic acid production and biomass during batch cultures of $P$. acidipropionici. Glycerol (closed square), glucose (open square), molar ratio of glycerol/glucose was $4 / 1$ (open circle), 2/1 (closed triangle), and 1/1 (closed circle), respectively; $\mathrm{pH}$ 6.5 controlled by $\mathrm{NaOH}$ addition; error bars data range about mean $(n \geq 2)$

formation of a more oxidized co-metabolite, such as acetic acid (reductance degree, 4.0) to achieve the redox balance; thus, a portion of the carbon flow is directed towards acetic acid formation from glucose, resulting in lower propionic acid yields [7]. During glycerol/glucose co-fermentation, glucose was often used as a hydrogen donor substrate to provide both reducing equivalents and ATP for biomass formation; nevertheless, glycerol was mainly used for propionic acid production. Using both substrates in cofermentation, a low concentration of acetic acid $\left(0.87 \mathrm{~g}^{-1}\right)$ and a high propionate/acetate molar ratio $(P /$ $A$ ) of 20.4 were obtained. This favorable co-fermentation could significantly increase the propionic acid yield, and thus further favoring the downstream processing of the products, as the efficiency of propionic acid extraction and purification by distillation and ion exchange is strongly limited by the presence of acetic acid [1].

Metabolic stoichiometric analysis (MSA) showed that, here, NADH and pyruvate may have played a key role in controlling or limiting propionic acid production. Pyruvate was found to be a common intermediate in the metabolic pathway going from glycerol or glucose to propionate as it could be disproportionated to propionate and acetate with NADH availability (Fig. 2). Insufficient supply of reducing equivalents would lead to a metabolic pathway shift toward acetate formation while, in contrast, an adequate supply of reducing equivalents would lead to a shift toward propionate formation. Moreover, when pyruvate is supplied in excess as an electron acceptor, that pyruvate is not only used as an electron acceptor but also oxidized to acetate [17]. Glycerol/glucose co-fermentation resulted in lower amounts of NADH and ATP required for the biomass formation [18], and thereby maintained an adequate supply of intracellular NADH. Thus, the present experimental results and metabolic stoichiometric analysis indicated a metabolic shift toward propionate formation, resulting in a significant increase of propionic acid production obtained in glycerol/glucose co-fermentation, compared to glucose or glycerol.

Furthermore, propionic acid production with this cofermentation strategy could also shorten the fermentation period from 168 to $144 \mathrm{~h}$, a clear advantage for propionic acid production (Table 1).

Fed-Batch Fermentation of Propionic Acid with Glycerol/Glucose Co-Fermentation Strategy

Fed-batch culture by feeding glycerol/glucose mixtures (4/1, mol/mol) was performed to maintain an approximate constant substrate concentration $\left(10 \mathrm{gl}^{-1}\right)$ (Fig. 6). At the end of the fermentation period $(192 \mathrm{~h})$, the propionic acid yield and substrate conversion efficiency were $29.2 \mathrm{gl}^{-1}$ and $54.4 \%$, respectively.

\section{Conclusion}

An effective co-fermentation strategy was employed to improve propionic acid production by $P$. acidipropionici. The optimal molar ratio of glycerol/glucose at $4 / 1$ (w/w) enhanced this production, with propionic acid yield and productivity increased $20 \%$ and $21 \%$, respectively, compared with optimal results from sole carbon sources (glycerol). Fed-batch results showed that the maximal propionic acid yield and substrate conversion efficiency could reach $29.2 \mathrm{gl}^{-1}$ and $54.4 \%$, respectively. The enhanced propionic 
Fig. 4 Comparison of specific growth rate $\left(\mu_{x}\right)$ and specific propionic acid formation rate $\left(\mu_{\mathrm{p}}\right)$ between glycerol and glycerol/glucose mixtures (a), and between glucose and glycerol/glucose mixtures (b)
A

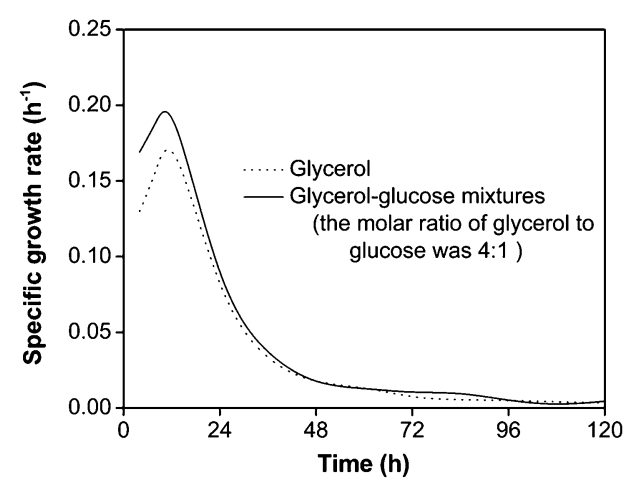

B

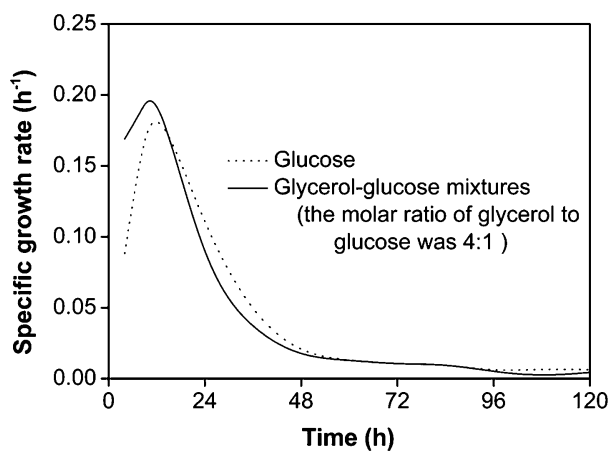

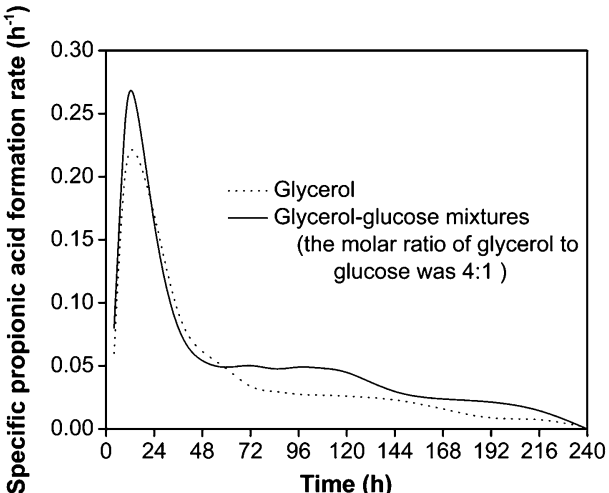

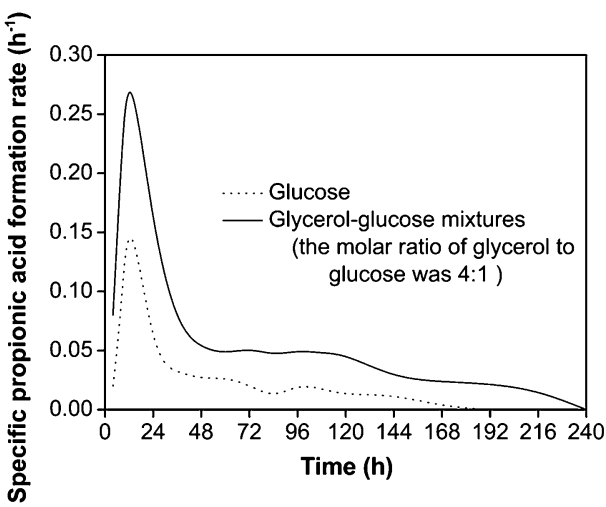

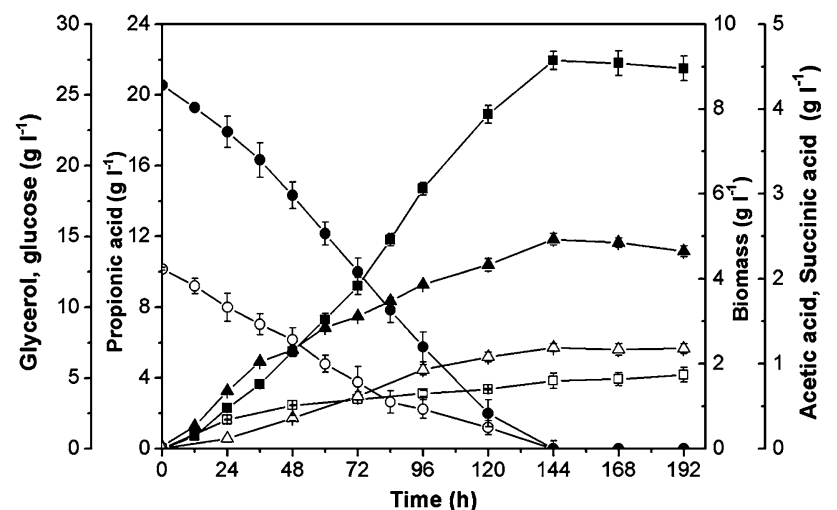

Fig. 5 Time course of glycerol/glucose co-fermentation and propionic acid production by $P$. acidipropionici. Biomass (closed triangle), glucose (open circle), glycerol (closed circle), propionic acid (closed square), succinic acid (open triangle), and acetic acid (open square); $\mathrm{pH} 6.5$ controlled by $\mathrm{NaOH}$ addition; error bars data range about mean $(n \geq 2)$

acid production and decreased byproducts formation obtained by using glycerol/glucose mixtures have the potential to facilitate simple and inexpensive downstream processing. This study offers an excellent alternative to conventional propionic acid fermentation. Nevertheless, it must be emphasized that further research is needed and is

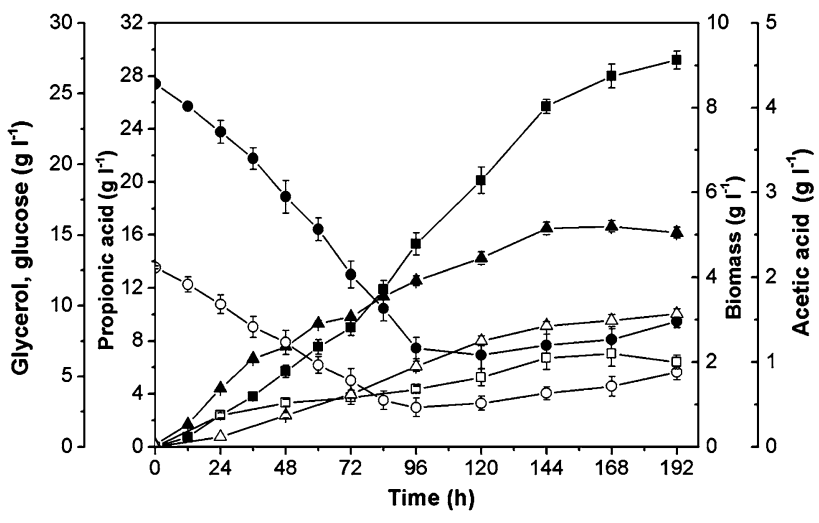

Fig. 6 Fed-batch fermentation of glycerol/glucose $(4 / 1, \mathrm{~mol} / \mathrm{mol})$ using P. acidipropionici. Biomass (closed triangle), glucose (open circle), glycerol (closed circle), propionic acid (closed square), succinic acid (open triangle), and acetic acid (open square); pH 6.5 controlled by $\mathrm{NaOH}$ addition; error bars data range about mean $(\mathrm{n} \geq 2)$

underway, such as regulation of the NADH supply and its impacts on fermentation.

Acknowledgments This study was supported by the National High Technology Research and Development Program of China (863 program) (No. 2009AA02Z210) and Technologies Research and Development Program of Qingdao (No. 07-2-1-25-nsh). 
Open Access This article is distributed under the terms of the Creative Commons Attribution Noncommercial License which permits any noncommercial use, distribution, and reproduction in any medium, provided the original author(s) and source are credited.

\section{References}

1. Barbirato F, Chedaille D, Bories A (1997) Propionic acid fermentation from glycerol: comparison with conventional substrates. Appl Microbiol Biotechnol 47:441-446

2. Berríos-Rivera SJ, San K-Y, Bennett GN (2003) The effect of carbon sources and lactate dehydrogenase deletion on 1, 2-propanediol production in Escherichia coli. J Ind Microbiol Biotechnol 30:34-40

3. Bok SH, Demain AL (1977) An improved colorimetric assay for polyols. Anal Biochem 81:18-20

4. Coral J, Karp SG, Porto de Souza Vandenberghe L, Parada JL, Pandey A, Soccol CR (2008) Batch fermentation model of propionic acid production by Propionibacterium acidipropionici in different carbon sources. Appl Biochem Biotechnol 151:333341

5. De Vries W, van Wyck-Kapteyn WM, Stouthamer AH (1973) Generation of ATP during cytochrome-linked anaerobic electron transport in propionic acid bacteria. J Gen Microbiol 76:31-41

6. Erickson LE, Minkevich IG, Eroshin VK (1979) Utilization of mass-energy balance regularities in the analysis of continuousculture data. Biotechnol Bioeng 21:575-591

7. Himmi EH, Bories A, Boussaid A, Hassani L (2000) Propionic acid fermentation of glycerol and glucose by Propionibacterium acidipropionici and Propionibacterium freudenreichii ssp. shermanii. Appl Microbiol Biotechnol 53:435-440

8. Lewis PV, Yang ST (1992) Propionic acid fermentation by Propionibacterium acidipropionici: effect of growth substrate. Appl Microbiol Biotechnol 37:437-442
9. Martínez-Campos R, Torre MDL (2002) Production of propionate by fed-batch fermentation of Propionibacterium acidipropionici using mixed feed of lactate and glucose. Biotechnol Lett 24:427-431

10. Papoutsakis ET (1984) Equations and calculations for fermentations of butyric acid bacteria. Biotechnol Bioeng 26:174-187

11. Papoutsakis ET, Meyer CL (1985) Fermentation equations for propionic-acid bacteria and production of assorted oxychemicals from various sugars. Biotechnol Bioeng 27:67-80

12. Rogers P, Chen JS, Zidwick MJ (2006) Organic acid and solvent production. In: Dworkin M, Falkow S, Rosenberg E et al (eds) The prokaryotes, vol 1, 3rd edn. Springer, New York, pp 611-619

13. San K-Y, Bennett GN, Berríos-Rivera SJ, Vadali RV, Yang Y-T, Horton E, Rudolph FB, Sariyar B, Blackwood K (2002) Metabolic engineering through cofactor manipulation and its effects on metabolic flux redistribution in Escherichia coli. Metab Eng 4:182-192

14. Suwannakham S, Yang ST (2005) Enhanced propionic acid fermentation by Propionibacterium acidipropionici mutant obtained by adaptation in a fibrous-bed bioreactor. Biotechnol Bioeng 91:325-337

15. Suwannakham S (2005) Metabolic engineering for enhanced propionic acid fermentation by Propionibacterium acidipropionici. Dissertation, The Ohio State University

16. VanBriesen JM (2002) Evaluation of methods to predict bacterial yield using thermodynamics. Biodegradation 13:171-190

17. Wagner N, Tran QH, Richter H, Selzer PM, Unden G (2005) Pyruvate fermentation by Oenococcus oeni and Leuconostoc mesenteroides and role of pyruvate dehydrogenase in anaerobic fermentation. Appl Environ Microbiol 71:4966-4971

18. Xiu ZL, Chen X, Sun YQ, Zhang DJ (2007) Stoichiometric analysis and experimental investigation of glycerol-glucose cofermentation in Klebsiella pneumoniae under microaerobic conditions. Biochem Eng J 33:42-52

19. Zhang A, Yang ST (2009) Engineering Propionibacterium acidipropionici for enhanced propionic acid tolerance and fermentation. Biotechnol Bioeng 104:766-773 